\title{
Effect of aging on silica aerogel properties
}

\author{
Subramaniam Iswar ${ }^{a, b}$, Wim J. Malfait ${ }^{a^{*}}$, Sandor Balog ${ }^{b}$, Frank Winnefeld ${ }^{c}$, Marco \\ Lattuada $a^{b}$ and Matthias M. Koebel ${ }^{a^{*}}$
}

${ }^{a}$ Laboratory for Building Energy Materials and Components, Swiss Federal Laboratories for Materials Science and Technology, Empa, Überlandstrasse 129, 8600 Dübendorf, Switzerland

${ }^{b}$ Adolphe Merkle Institute, University of Fribourg, 1700 Fribourg, Switzerland ${ }^{c}$ Laboratory for Concrete and Construction Chemistry, Swiss Federal Laboratories for Materials Science and Technology, Empa, Überlandstrasse 129, 8600 Dübendorf, Switzerland

*Correspondingauthors: wim.malfait@empa.ch, matthias.koebel@empa.ch. 


\section{Graphical abstract}
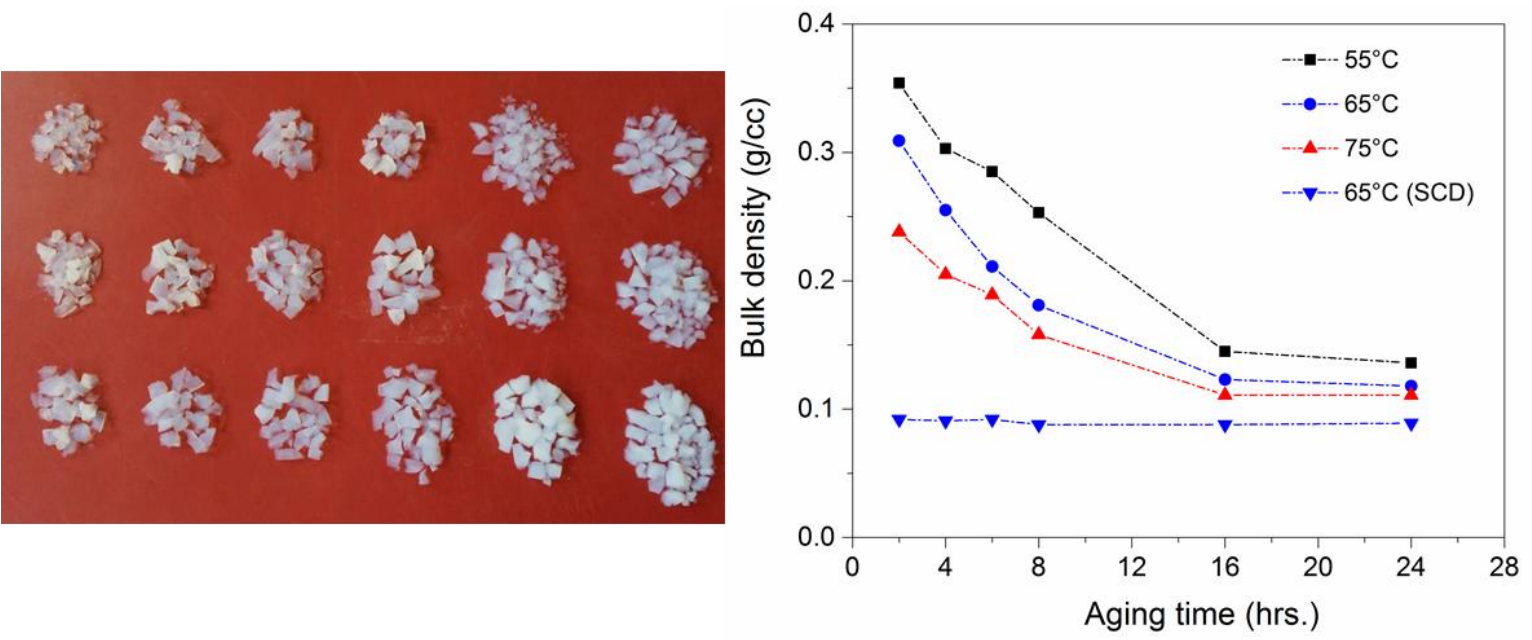


\begin{abstract}
Silica aerogel's unique physical and chemical properties make them fascinating materials for a wide variety of applications. In addition to hydrophobization by silylation, aging is very important in the synthesis of silica aerogel by ambient pressure drying. Here we systematically study the effect of aging on the physico-chemical properties of silica aerogel with emphasis on ambient dried materials. Silica gels were aged for different times and at different temperatures in their gelation liquid (without solvent exchange), hydrophobized in hexamethyldisiloxane and subsequently dried either at ambient pressure or from supercritical $\mathrm{CO}_{2}$. Dynamic oscillatory rheological measurements demonstrate that aging reinforces the alcogels, particularly at high strain rates. The specific surface area decreases with increasing aging time and temperature as a consequence of Ostwald ripening processes during aging. With increasing aging time and temperature, the linear shrinkage and bulk density decrease and the pore size and pore volume increase for the ambient dried gels, but remain nearly constant for supercritically dried gels. Small-Angle X-ray scattering does not detect significant structural changes at length scales smaller than about hundred nanometers, but hints at systematic variations at larger length scales. The findings of this study highlight the importance of aging to increase the ability of the gel particle network to withstand irreversible pore collapse during ambient pressure drying.
\end{abstract}

Keywords: aerogel; aging; solid-state NMR; SAXS; BET. 


\section{Introduction}

Aerogels are predominantly mesoporous solids with a range of extreme material properties. They consist of a three-dimensional nanoparticle network with interstitial mesopores. They owe their outstanding properties to this unique structure with low densities, high meso-porosities and specific surface areas $[1,2]$. The most widely exploited property of silica aerogels is its low thermal conductivity leading to prominent applications as high performance thermal insulation. Silica aerogels are thermal superinsulators with thermal conductivities as low as $12 \mathrm{~mW} /(\mathrm{m} \cdot \mathrm{K})$, i.e., less than half the value of conventional insulation, because of their small pore sizes in the order of the mean free path of air, limiting the gas phase conduction $[3,4]$. Aerogels also find use in other applications, such as waste management (gas absorption, radioactive waste confinement), laser experiments, sensors (ultrasonic and gas) [5], nuclear particle detection (Cherenkov), optics (light-guides) [6], Knudsen pump [7], electronic devices, capacitors, high explosive research and catalysts [8].

Classical silica aerogels are synthesized by gelation and aging of a colloidal silica sol commonly from alkoxide precursors such as tetramethoxysilane (TMOS) or tetraethoxysilane (TEOS) [9-11]. The entrapped solvent is then removed from the wet gel by drying. Supercritical drying necessitates the use of high pressure instrumentation resulting in a costly production process, but effectively maintains the high porosity of the gel [12-14]. On the other hand, ambient pressure drying (APD) is competitive in terms of cost and safety, and has been studied over many years, but requires an additional silylation or modification step before the evaporative drying wherein the polar silanol surface chemical groups are replaced by non-polar hydrophobic groups. 
This modification step promotes the so-called spring-back effect as the solvent front retreats and capillary stresses are released, restoring the porosity of the gel after solvent evaporation [15-18]. A considerable amount of work has already been published about the modification step (before APD) to synthesize low density hydrophobic silica aerogels [19-34].

The mechanical properties of silica aerogel depend to a large extent on the processing conditions. Despite its importance, aging has not been studied systematically in the literature. Silica gels consist of a pearl-necklace structure where silica nanoparticles are linked together by inter-particle necks, the weak links in the gel structure [14,35]. Aging enhances the strength and stiffness of the wet gel and is critical to prevent the pore collapse of gels under the strong capillary forces that occur during APD. Several studies reported on the influence of the aging conditions used during silica aerogel synthesis [36-59]. Many studies reported the strengthening of wet silica gels by means of an exchange into a silane precursor containing solution (TEOS or TMOS), a process more akin to a surface modification step, which prevents the cracking of silica aerogel during supercritical drying [39-42,44-47,49,50,53,54]. Several studies have also reported on making the gels more rigid by aging them for extended periods of time (multiple days or even weeks) which helps in reducing the shrinkage of the final aerogels produced after supercritical drying [36,37,43,48,56]. In other studies, Davis et al. [38] studied the effect of different pore fluids on aging process which helps to prevent the pore collapse upon ambient drying and Reichenauer [51] showed that heat treatment of silica gels in water increased the mechanical stability which enables supercritical drying without significant shrinkage of the gel. In summary, most of these studies indicate that long aging times and several solvent exchanges before drying are typically employed during 
the synthesis of silica aerogels. The effect of both aging and drying processes on the final physico-chemical properties of silica aerogels was investigated for SCD TEOS based silica aerogels $[55,57]$ and for APD water-glass based silica aerogels $[52,58,59]$.

The aim of this work is to see the effect of aging at industrially reasonable timescales, i.e. up to 24 hours, on the TEOS based silica gel structure and their ability to withstand ambient pressure drying. We systematically investigate the influence of different aging times (from 2 to 24 hours) and temperatures $\left(55,65 \& 75^{\circ} \mathrm{C}\right)$ on the physico-chemical properties of the aerogels. Contrary to many previous studies, this work does not involve an exchange into a silane precursor solution, but is confined to aging within the gelation solution (native pore fluid). Silica gels aged for different times and at different temperatures were then hydrophobized and dried either at ambient pressure or from supercritical $\mathrm{CO}_{2}$. The aerogels were characterized in terms of surface chemistry and microstructure. We observed that the bulk density of ambient dried aerogels decreases as the aging time increases and at different aging temperatures. On the other hand, there was no significant difference in the bulk density of aerogels at different aging times when dried supercritically. Hence, the aging process has a particularly profound influence on the silica aerogel synthesis via ambient pressure drying. 


\section{Experimental section}

\subsection{Aerogel synthesis}

All silica aerogels were prepared according to the process scheme as depicted in Figure $1.9 \mathrm{ml}$ of polyethoxydisiloxane (PEDS), a prepolymerized form of tetraethyl orthosilicate (TEOS) containing a water-to-TEOS molar ratio of 1.5 and a $\mathrm{SiO}_{2}$ content of $20 \% \mathrm{w} / \mathrm{w}$ in ethanol (referred to as PEDS- $\mathrm{P}_{750 \mathrm{E} 20}$ ) was used as the silica source [60] and diluted with $21 \mathrm{ml}$ of ethanol (F25-AF-MEK, absolute ethanol denatured with 2 vol.\% methyl ethyl ketone) and with $1 \mathrm{ml}$ of distilled water under constant stirring conditions for 5-10 minutes at room temperature. Gelation occurred approximately 10 minutes after the addition of $0.36 \mathrm{ml}$ of $5.5 \mathrm{M}$ ammonium hydroxide solution $\left(\mathrm{NH}_{4} \mathrm{OH}\right.$ in water). The gels were covered with an additional $0.4 \mathrm{ml}$ of ethanol to prevent exposure to the air due to solvent evaporation during aging, and aged at different times $(2,4,6,8,16$ and 24 hours $)$ and temperatures $\left(55,65 \& 75^{\circ} \mathrm{C}\right)$. The sample boxes were closed, but not sealed and aging took place at atmospheric pressure. The aged gels were hydrophobized by soaking them in a mixture of $60 \mathrm{ml}$ of hexamethyldisiloxane (HMDSO), $0.24 \mathrm{ml}$ of concentrated hydrochloric acid (37\% purity) and $2.2 \mathrm{ml}$ of ethanol at $65^{\circ} \mathrm{C}$ for 24 hours. The hydrophobized gels were dried at ambient pressure for 2 hours at $150^{\circ} \mathrm{C}$. An additional series of hydrophobized gels, aged at $65^{\circ} \mathrm{C}$, was dried in an autoclave (4334/A21-1, Separex, France) from supercritical carbon dioxide (SCD). The autoclave of the supercritical dryer was filled with ethanol prior to loading the samples to minimize exposure to air which can cause the gels to crack. Once the chamber was sealed, the remainder of the chamber was filled from the top with liquid $\mathrm{CO}_{2}$ and the ethanol was slowly released from the bottom of the chamber. After multiple flushing steps with liquid $\mathrm{CO}_{2}$ during $\sim 24$ hours to exchange the ethanol with $\mathrm{CO}_{2}$, the autoclave was isolated from the $\mathrm{CO}_{2}$ supply (all valves closed) and heated for 
3 hours to $48^{\circ} \mathrm{C}$, which resulted in a pressure increase to 150 bar and brought the previously liquid $\mathrm{CO}_{2}$ to the supercritical state. The chamber was then gradually depressurized by releasing gaseous $\mathrm{CO}_{2}$ from the venting valve over approximately one hour and allowed to cool before the samples were removed from the chamber.

\subsection{Characterization}

\subsubsection{BET analysis}

The apparent bulk density was determined from the mass and volume, which was measured by powder displacement method (Micromeritics GeoPyc 1360). The specific surface area $\left(\mathrm{S}_{\mathrm{BET}}\right)$ was determined from the nitrogen sorption isotherms (Micromeritics TriFlex) using Brunauer-Emmet-Teller (BET) analysis [61]. The pore volume $\left(\mathrm{V}_{\text {pore }}\right)$ was calculated from the bulk and skeletal density of the aerogel (Equation 1). The average pore diameter was calculated from the pore volume and surface area (Equation 2) rather than the Barrett-Joyner-Halenda $(\mathrm{BJH})$ analysis [62], which for aerogels is affected by mechanical deformation in the desorption branch of the capillary condensation range and is in effect a second drying of the gel from liquid nitrogen including a deformation with spring-back [63]. Estimated uncertainties for bulk density are $5 \%$ relative. The precision on the BET surface area is around $10 \mathrm{~m}^{2} / \mathrm{g}$, but the accuracy is lower $\left(\sim 50 \mathrm{~m}^{2} / \mathrm{g}\right)$ because the BET surface areas are model and fit dependent. The uncertainties on the pore diameter and pore volume are estimated to be on the order of $10 \%$. For the pore volume calculations, a skeletal density of approximately $2.0 \mathrm{~g} / \mathrm{cm}^{3}$ was used [64].

$$
\begin{aligned}
& \mathrm{V}_{\text {pore }}=\frac{1}{\rho_{\text {bulk }}}-\frac{1}{\rho_{\text {skeletal }}} \\
& \mathrm{D}_{\text {pore }}=\frac{4 . \mathrm{V}_{\text {pore }}}{\mathrm{S}_{\mathrm{BET}}}
\end{aligned}
$$




\subsubsection{Small-Angle X-Ray scattering (SAXS) measurements and data interpretation}

Small-angle X-ray scattering spectra were recorded using a NanoMax-IQ camera (Rigaku Innovative Technologies, Auburn Hills, USA). The samples were kept in vacuum at room temperature during the measurements. Raw data was processed according to standard procedures, including correction for detector non-linearity and the subtraction of any background scattering. Given that the samples showed isotropic scattering patterns, data correction is followed by azimuthally averaging, and the data are plotted as a function of the momentum transfer, $q=4 \pi \cdot \lambda^{-1} \cdot \sin (\theta / 2)$, where $\theta$ is the scattering angle and $\lambda=0.1524 \mathrm{~nm}$ is the photon wavelength. As the thickness varied from sample to sample and could not be measured due to irregular sample shapes, the scale of the scattering intensity is arbitrary and we only interpret the shape of the curves.

\subsubsection{Electron microscopy}

Scanning electron microscopy (SEM) images were obtained with a FEI Nova NanoSEM 230 instrument (FEI, Hillsboro, Oregon, USA) at an accelerating voltage of $10 \mathrm{kV}$ and a working distance of $5 \mathrm{~mm}$. The silica aerogels were fixed on the sample holder using a carbon pad and subsequently coated with $15-20 \mathrm{~nm}$ of platinum for SEM analysis. Transmission electron microscopy (TEM) images were recorded with a JEOL-2200FS microscope operating at an accelerating voltage of $200 \mathrm{kV}$. The aerogel samples were crushed and dispersed in methanol and the resulting dispersion was drop-cast onto a $\mathrm{Cu} / \mathrm{C}$ grid and then allowed to evaporate at room temperature.

\subsubsection{NMR, FTIR and elemental analysis}

All Nuclear Magnetic Resonance (NMR) spectra were collected with magic angle spinning (MAS) on a Bruker Avance III system equipped with a wide-bore $9.4 \mathrm{~T}$ magnet, corresponding to Larmor frequencies of 400.2 MHz for ${ }^{1} \mathrm{H}$ and $79.5 \mathrm{MHz}$ for

${ }^{29} \mathrm{Si}$. Quantitative solid state ${ }^{1} \mathrm{H}$ spectra of the aerogel samples were collected in $2.5 \mathrm{~mm}$ 
zirconia rotors with a $24 \mathrm{kHz}$ MAS rate to maximize the resolution and with a pulse delay in excess of 5 times the $T 1$ relaxation time to ensure complete relaxation. ${ }^{1} \mathrm{H}^{29}{ }^{29} \mathrm{Si}$ cross polarization MAS NMR spectra were recorded with a MAS rate of $4 \mathrm{kHz}$ in $7 \mathrm{~mm}$ zirconia rotors to maximize the sensitivity. All spectra were processed with matNMR [65] and calibrated according to a previously described procedure [34,66] (Figure S6). Fourier Transform Infrared Spectroscopy (FTIR) spectroscopy was carried out on a Bruker Tensor 27 spectrometer. Samples were analysed in attenuated total reflectance (ATR) mode using a diamond crystal. The carbon and hydrogen content were determined by standard elemental analysis (combustion and subsequent gas-phase FTIR analysis) at the Laboratory for Organic Chemistry of ETH Zurich.

\subsubsection{Mechanical characterization of silica alcogels}

Dynamic oscillatory rheological measurements of silica alcogels (before the silylation step) aged at $65^{\circ} \mathrm{C}$ for 6 different aging times were performed on modular compact rheometer MCR300 (Anton Paar Physica) with a profiled parallel plate measuring system ( $50 \mathrm{~mm}$ in diameter). Strain sweep tests were carried out on 6-8 $\mathrm{mm}$ thick, round silica alcogel discs in the strain range from $0.01-100 \%$ at a fixed frequency of 1 $\mathrm{rad} / \mathrm{s}$ a typical strain rate for rheology measurements of gels, polymers and emulsions [67-69]. During all measurements, a constant temperature of $20^{\circ} \mathrm{C}$ was maintained by a Peltier control unit. The generated normal force averages between 0 and $2 \mathrm{~N}$ during the tests. Since silica alcogels are very weak compared to more commonly tested materials, care was taken to minimize the structural damage during the sample loading. Nevertheless, some of the individual measurements produced spurious results, as is typical for measurements on weak samples. Therefore, six measurements were performed for each aging time and the results were averaged after the removal of 
statistically obvious outliers. Aside from those outliers, the experimental data were reproducible with a relative error of $10 \%$.

\section{Results}

\subsection{Bulk density and linear shrinkage}

The aerogel bulk density and pore volume of silica aerogels prepared by APD is strongly affected by the aging conditions (Table 1, Figure 2 and Figure 3), in contrast to the aerogels prepared by SCD. The APD silica aerogel density decrease with increasing aging time and this is observed at all aging temperatures. For all temperatures, the density decrease is most pronounced at short aging times with a nearly constant density for aging times of 16 hours and above (Figure 3a). The typical blue hues associated with silica aerogel are more prominent for longer aging times or higher temperatures (Figure 2).

\subsection{Microstructural analysis}

The silica aerogels display the typical pearl-necklace morphology with silica particles linked by inter-particle necks, regardless of the aging time (Figure 4). The TEM analysis was not conclusive in visualizing systematic differences in the neck regions for samples prepared with different aging times. The SEM images display typical silica aerogel morphologies with mesopores enclosed by secondary particle aggregates of 20-50 $\mathrm{nm}$ in diameter (Figure S2). SEM images reveal a rather coarse raspberry like particle aggregate substructure and again, no systematic microstructural variations could be discerned for the different aging times.

All aerogel samples display nitrogen sorption isotherms with type IV hysteresis loops characteristic for mesoporous materials (Figure 5 and Figure S3) [70]. The amount of adsorbed nitrogen at high relative pressures (pore volume) increases with increasing 
aging time and temperature for the APD aerogels (Figure 5a) but remains nearly constant for the SCD aerogels (Figure 5b), consistent with structural collapse leading to density and porosity variations as a function of aging time for the APD and SCD aerogels, respectively (Figure 3). For both the APD and SCD aerogels, the hysteresis loops become narrower with increasing aging time (Figure 5) and temperature (Figure S3 and Figure S4).

All aerogels display high specific surface areas between 800 and $1000 \mathrm{~m}^{2} / \mathrm{g}$, with higher surface areas for the SCD aerogels compared to the APD samples for a given aging time (Table 1, Figure 6a). The surface areas decrease only slightly with increasing aging time $(<10 \%)$ which means that pores collapse but the silica structure does not fuse together. The average pore sizes and pore volumes strongly increase for the APD samples with increasing aging time, but the effect is much more limited for the SCD samples (Table 1, Figure $6 \mathrm{~b}$ and Figure $3 \mathrm{~b}$ ). The variations in pore size are primarily related to the variations in density and pore volume (Figure 3), rather than the variation in surface area.

\subsection{SAXS spectra analysis}

The SAXS spectra as a function of q of APD aerogels aged at $65^{\circ} \mathrm{C}$ are shown in Figure 7 (in double logarithmic scale), while the SAXS spectra of all other samples are displayed in Figure S10 and Figure S11. A common feature of all measured SAXS spectra is the presence of some scale invariance. This can be observed as the power law regime, appearing as linear in a double logarithmic plot, which is compatible with a fractal model. The slope of this part provides the fractal dimension of the aerogel. However, the lower q values of the spectra suggest that the scale invariance is limited, that is, the aerogels are made of clusters of finite size. Thus, the following model for the density correlation function has been used to interpret the results [71]: 


$$
\gamma(r)=\left\{\begin{array}{c}
1 \text { for } 0 \leq r<r_{0} \\
e^{-\frac{r-r_{0}}{\zeta}}\left(\frac{r}{r_{0}}\right)^{d_{f}-3} \text { for } r \geq r_{0}
\end{array}\right.
$$

In equation (3), $\mathrm{r}_{0}$ is the size of the primary 'building blocks' of the fractal structure (e.g. $r_{0}$ is the radius of the primary particles making the aerogel), $d_{f}$ the fractal dimension and $\zeta$ the characteristic cluster length scale.

The scattering intensity as a function of the scattering vector can be determined via the radial Fourier transformation of the density correlation function $\gamma(\mathrm{r})$, where in the case of isotropic structure, which is the case for aerogels one obtains the following equation:

$$
\mathrm{I}(\mathrm{q})=4 \pi \int_{0}^{\infty} \gamma(\mathrm{r}) \frac{\sin (\mathrm{qr})}{\mathrm{qr}} \mathrm{r}^{2} \mathrm{dr}
$$

Another feature of these SAXS spectra is the presence of two regimes with distinct scaling characteristics. The first regime ends at q values of about $1.5-2.5 \mathrm{~nm}^{-1}$ (fractal regime), while the second one ends at q values of about $7 \mathrm{~nm}^{-1}$ (Porod regime). For long aging times and low densities, the fractal regime extends over a larger range in $\mathrm{q}$ compared to short aging times and high densities. A similar density dependence of silica aerogels was previously observed by Woignier et al. [72].

Therefore, each SAXS spectrum was fitted with a bimodal expression of the density correlation function, obtained by the linear combination of two modes: $\gamma(\mathrm{r})=\mathrm{A} \gamma_{1}(\mathrm{r})+(1-$ A) $\gamma_{2}(r)$, where $1>A>0$ and $\gamma_{1}(r)$ and $\gamma_{2}(r)$ are two functions of type (3), with different parameter values. This expression was able to describe each spectrum very well, and resulted in four parameters: $\zeta_{1}, \zeta_{2}, \mathrm{~d}_{\mathrm{f} 1}, \mathrm{~d}_{\mathrm{f} 2}$ for each aerogel sample.

Of these four parameters, the characteristic cluster length scale $\zeta_{1}$ and the fractal dimension $\mathrm{d}_{\mathrm{fl}}$ are the most important ones. A close inspection of the fractal dimension values shows that fitting the SAXS spectra by means of equations (3) and (4) indicate that, under all conditions, $d_{f 1}$ is almost constant, with a value of about 2.7 (Figure 8a). 
This high value is indicative of a dense packing of primary particles forming the aerogel, at least in the size range up to 50-60 $\mathrm{nm}$. The independence of this value on the aging time and temperature indicates that the aging process does not affect the packing of the primary particles. Even though SAXS data do not cover size range beyond $60 \mathrm{~nm}$, the minor differences in SAXS spectra at low q values (Figure 7) indicate that the characteristic size of the clusters slightly increases as the aging time increases for the APD samples. In the case of SCD samples, instead, only negligible changes are observed (Figure $\mathrm{S} 10$ ). Figure $8 \mathrm{~b}$ shows the characteristic cluster length scale $\zeta_{1}$ as a function of aging time, for the different conditions. A clear increase is visible in the cluster length scale with increasing aging time for the APD samples, but only a moderate increase is observed for SCD samples. Overall, the SAXS investigation indicates that the aging process does not significantly affect the structure of aerogels at length scales smaller than hundred nanometers. Under our measurement conditions, the SAXS experiments appear not to be sensitive to the structural changes due to dissolution-reprecipitation and the reinforcement of inter-particle necks that are inferred from the surface area, NMR measurements and rheology data. The SCD reference samples, whose microstructures closely resemble those of the alcogels, have nearly identical SAXS curves for different aging times. This indicates that the observed changes in the SAXS data of the APD samples are mostly related to structural changes during the APD process, rather than structural changes in the alcogels during aging.

\subsection{Surface chemistry}

The surface chemistry, as probed by quantitative solid state ${ }^{1} \mathrm{H}$ NMR spectroscopy (Figure 9a) and FTIR spectroscopy (Figure S5) display no significant variations as a function of aging time and temperature beyond surface area effects. The ${ }^{1} \mathrm{H}$ NMR 
spectra display the peaks typical for silylated silica aerogels prepared from an ethanolic sol: a peak $0.3 \mathrm{ppm}$ related to the trimethylsilyl groups (TMS) groups and a pair of peaks at 1.3 and 3.8 ppm related to methyl $\left(-\mathrm{CH}_{2}-\mathrm{CH}_{3}\right)$ and methylene $\left(-\mathrm{CH}_{2}-\mathrm{CH}_{3}\right)$ units originating from surface ethoxy groups[66]. The ${ }^{1} \mathrm{H}$ NMR data, and to a lesser extent the FTIR data, resolve a minor decrease in the total TMS and ethoxy content that tracks the decrease in surface area (Figure S7, Table S1): the surface density of TMS and ethoxy is constant at around $2.0 \pm 0.1$ and $1.0 \pm 0.1$ molecules per $\mathrm{nm}^{2}$ respectively, but the surface area reduction due to aging (Figure 6a) results in a decrease of the surface groups, which is also evident from the elemental analysis (Table S2). The ${ }^{1} \mathrm{H}-$

${ }^{29} \mathrm{Si}$ cross polarization (CP) MAS NMR spectra (Figure S8) also confirm that all samples are silylated to the same degree. Thus, the above described variations of the aerogel properties as a function of aging time are not related to differences in hydrophobization but because of increase in strength and stiffness of the gel network and reduced pore collapse as aging time increases.

With increasing aging time, the intensity of the peak assigned to $Q^{3}$ decreases relative to that of $\mathrm{Q}^{4}$, where $\mathrm{Q}^{\mathrm{n}}$ is a Si atom coordinated by ' $\mathrm{n}$ ' bridging oxygen atoms linked to ' $\mathrm{n}$ ' Si next-nearest neighbours, and 4-n non-bridging oxygen atoms in the form of ethoxy or hydroxyl groups (Figure 9b). The decrease in $\mathrm{Q}^{3}$ indicates a higher degree of condensation with increasing aging time.

\subsection{Mechanical properties of silica alcogels}

The oscillatory sweep tests of silica alcolgels aged at $65^{\circ} \mathrm{C}$ for 6 different aging times display typical $G^{\prime}$ and $G^{\prime \prime}$ curves for cross-linked polymers, fumed silica suspensions, rubbers, polysaccharide based alcogels type materials etc. [67-69] (Figure 10). The 
storage modulus $\left(\mathrm{G}^{\prime}\right)$ is a measure of the deformation energy stored by the sample during the shear process which represents the elastic behaviour of the material whereas loss modulus ( $\mathrm{G} ")$ is a measure of the deformation energy used by the sample during the shear process which represents the viscous behaviour of the material. At low deformation strain, in the so-called linear viscoelastic (LVE) range, both G' and G" display constant plateau values and the elastic component prevails the viscous one ( $\mathrm{G}^{\prime}$ $>$ G") which indicates the full elasticity of the silica alcogels for low deformation strains (up to 5\%) for all aging times (Figure 10). The values for $\mathbf{G}^{\prime}$ and $\mathbf{G}^{\prime \prime}$ do not vary systematically as a function of aging time within the linear viscoelastic regime (Figure S13). At higher deformation strains, the structure starts to break down and the response is no longer fully elastic: $G^{\prime}$ decreases and $G^{\prime \prime}$ increases leading to a crossover point where G' equals G". The crossover strain where G" equals G' occurs near $30 \%$, independent of the aging time, but the values of $G^{\prime}$ and $G^{\prime \prime}$ at the crossover point do vary systematically with aging time: both $G^{\prime}$ and $G^{\prime \prime}$ increase from $\sim 150$ to $\sim 800$ Pa for an increase in aging time from 2 to 24 hrs (Figure S13). Beyond the crossover point ( $>\mathbf{3 0} \%$ strain), the range of irreversible deformation is entered wherein the state of elastic behaviour passes into viscous behaviour ( $G^{\prime \prime}$ > $\left.G^{\prime}\right)$ and the gel network is disrupted by the oscillatory shear force. Nevertheless, the values of $G^{\prime}$ and $G^{\prime \prime}$ continue to increase systematically as a function of aging time, e.g. $\mathrm{G}^{\prime \prime}$ is $16 \mathrm{~Pa}$ for $2 \mathrm{hrs}$, but $116 \mathrm{~Pa}$ for $24 \mathrm{hrs}$ of aging and $\mathrm{G}^{\prime}$ is $0.6 \mathrm{~Pa}$ for 2 hrs, but 36 Pa for 24 hrs of aging at a deformation strain of 100\% (Figure S13). In summary, the rheology data shows that aging does not affect the purely elastic response of the silica gels, but strongly increases $G^{\prime}$ and $G^{\prime \prime}$ in the viscous regime. 


\section{Discussion}

The reduction in surface area with aging time for both the APD and SCD aerogels demonstrates that aging is a dissolution-re-precipitation process akin to Ostwald ripening. A reduction in surface area with aging time and temperature was also observed in previous studies for silica xerogels/ aerogels when exchanged into a silane precursor solution (TEOS or TMOS) before aging or when aged for very long times $[38,44,46,55]$. During the aging process, the strength and stiffness of the gel framework increase due to an increased degree of condensation reactions and siloxane cross linking within the gel network ( $\equiv \mathrm{Si}-\mathrm{OH}+\mathrm{OH}-\mathrm{Si} \equiv \rightarrow \equiv \mathrm{Si}-\mathrm{O}-\mathrm{Si} \equiv)$, solution-precipitation of silica and attachment of unreacted oligomers from the gelation process (Figure 9b) [12,37,38]. Material is transported to the inter-particle necks between the primary silica particles which grow, leading to a more rigid gel network. An increase in aging temperature increases the kinetics of this process whereas an increase in aging time allows more time for these reactions to take place: together, both lead to higher mechanical stiffness of the particle network structure. This coarsening mechanism in which silica species dissolve and re-precipitate onto the existing particle network and inter-particle necks is driven by a surface free energy minimization through a decrease in surface area [12]. Aging reinforces the inter-particle necks leading to an increased strength of the gel network as confirmed from the dynamic rheology measurements of silica alcogels under oscillatory shear, particularly at high strain (Figure 10 and Figure S13). The higher $\mathbf{G}^{\prime}$ and $G^{\prime \prime}$ values for long aging times at, and beyond, the crossover point confirm the reinforcement of the necks between the primary silica nanoparticles. This reinforcement leads to silica gels that have been aged longer can better tolerate the large deformation strains that occur during ambient pressure drying, resulting in 


\section{a more pronounced spring-back effect and smaller degree of permanent}

\section{densification.}

The nitrogen sorption data also hints at the strengthening of the particle network with increasing aging time. The desorption branch of the isotherm is in effect a second drying of the gel from liquid nitrogen, including a deformation with spring-back and a narrower hysteresis is indicative of smaller mechanical deformation [63]. For the SCD aerogels, increased aging times lead to a narrower hysteresis (Figure 5b), which is consistent with a reduced mechanical deformation. For the APD aerogels, increased aging times also lead to a narrower hysteresis (Figure 5a), but the shapes of the isotherms are also influenced by the different densities and pore sizes (Figure 3 and Figure 6b). Overall, the BET analysis highlights the importance of aging to allow the gel particle network to withstand shrinkage and pore collapse under the strong capillary forces present during ambient pressure drying.

The strengthening during aging allows the gel network to withstand the capillary stresses during ambient pressure drying, resulting in a reduced linear shrinkage and a lower bulk density of APD silica aerogel with increasing aging time and temperature (Figure 2 and Figure 3) which were previously also observed for APD water-glass based silica aerogels $[52,58,59]$. In contrast, there is no difference in the bulk density with different aging times for SCD silica aerogels because the supercritical drying process eliminates the capillary stresses and forces during drying and hence, leads to very little shrinkage, regardless of the strength of the gel network. Therefore, variations in the aging process have no significant influence on the density and pore volume of silica aerogel when dried supercritically similar to results shown by Strøm et al. for SCD TEOS based silica aerogels [55]. 
The combination of rheology, density and porosity data allows us to conclude that aging processes affect the structure of aerogels at very small length scales through dissolutionreprecipitation and the reinforcement of inter-particle necks. For ambient pressure drying, but not for supercritical drying, the SAXS data (Figure 7) hints at structural changes at length scales larger than hundred nanometers, presumably due to changes in the packing density of the secondary particles. At intermediate length scales, aging has at most a minor effect on the microstructure for both APD and SCD aerogels (Figure 7 and Figure S10).

\section{Conclusions}

Our study demonstrates that aging within the gelation liquid, i.e., without resorting to a solvent exchange, and/or addition of additional silane monomers (TEOS/TMOS), effectively strengthens the gel network and enables the production of low density, silica aerogels by APD. Aging times of multiple days or even weeks as often described in the scientific literature are not realistic for industrial aerogel production, but can be strongly reduced by aging at higher temperatures. Aging strengthens the inter-particle necks of the silica gel pearl-necklace structure through dissolution-reprecipitation processes akin to Ostwald ripening that are driven by the energy minimization through the reduction of total surface area. The drying process magnifies the effects of aging on the gel structure and stability, with a strong irreversible pore collapse for poorly aged samples due to the strong capillary forces and mechanical deformation (spring-back effect) that occur during ambient pressure drying but are mostly absent during supercritical drying. Both aging and hydrophobization are equally essential conditions for the successful synthesis of low density silica aerogels by ambient pressure drying. 


\section{Acknowledgements}

We would like to thank Shanyu Zhao for assistance in experimental design, Yucheng Zhang for TEM analysis, and the Laboratory for Organic Chemistry at ETH Zurich for the elemental analysis. Marco Lattuada gratefully acknowledges financial support from the Adolphe Merkle foundation and from the Swiss National Science Foundation, with grant numbers PP00P2133597/1 and PP00P2_159258.

\section{References}

[1] N. Hüsing, U. Schubert, Angew. Chemie Int. Ed. 37 (1998) 22-45.

[2] E. Cuce, P.M. Cuce, C.J. Wood, S.B. Riffat, Renew. Sustain. Energy Rev. 34 (2014) 273-299.

[3] M. Koebel, A. Rigacci, P. Achard, J. Sol-Gel Sci. Technol. 63 (2012) 315-339.

[4] S.B. Riffat, G. Qiu, Int. J. Low-Carbon Technol. 8 (2013) 1-6.

[5] M. Schmidt, F. Schwertfeger, J. Non. Cryst. Solids 225 (1998) 364-368.

[6] L.W. Hrubesh, J. Non. Cryst. Solids 225 (1998) 335-342.

[7] S. Zhao, B. Jiang, T. Maeder, P. Muralt, N. Kim, S.K. Matam, E. Jeong, Y.L. Han, M.M. Koebel, ACS Appl. Mater. Interfaces 7 (2015) 18803-18814.

[8] J.L. Gurav, I.-K. Jung, H.-H. Park, E.S. Kang, D.Y. Nadargi, J. Nanomater. 2010 (2010) 1-11.

[9] S.J. Teichner, G.A. Nicolaon, M.A. Vicarini, G.E.E. Gardes, Adv. Colloid Interface Sci. 5 (1976) 245-273.

[10] R.C. Mehrotra, J. Non. Cryst. Solids 145 (1992) 1-10.

[11] A. Soleimani Dorcheh, M.H. Abbasi, J. Mater. Process. Technol. 199 (2008) 1026.

[12] G.W. Scherer, J. Non. Cryst. Solids 100 (1988) 77-92.

[13] M.J. van Bommel, A.B. de Haan, J. Non. Cryst. Solids 186 (1995) 78-82.

[14] M.A. Aegerter, N. Leventis, M.M. Koebel, Advances in Sol-gel Derived Materials and Technologies, Springer New York, 2011.

[15] G.. Pajonk, S.J. Tichner, Proceedings of the First International Symposium on Aerogels, Springer-Verlag, Wurzburg, 1985.

[16] D.M. Smith, R. Deshpande, J.C. Brinker, Mater. Res. Soc. 271 (1992) 567-572.

[17] D.M. Smith, D. Stein, J.M. Anderson, W. Ackerman, J. Non. Cryst. Solids 186 (1995) 104-112.

[18] F. Schwertfeger, D. Frank, M. Schmidt, J. Non. Cryst. Solids 225 (1998) 24-29.

[19] A. Bisson, A. Rigacci, D. Lecomte, E. Rodier, P. Achard, Dry. Technol. 21 (2003) 593-628.

[20] C.J. Lee, G.S. Kim, S.H. Hyun, J. Mater. Res. 37 (2002) 2237-2241.

[21] F. Shi, L. Wang, J. Liu, Mater. Lett. 60 (2006) 3718-3722.

[22] A.P. Rao, A.V. Rao, G.M. Pajonk, Appl. Surf. Sci. 253 (2007) 6032-6040.

[23] J.G. Yeo, J.M. Hong, C.H. Cho, S.D. Bhagat, Y.H. Kim, Y.S. Ahn, Solid State Phenom. 124-126 (2007) 675-678.

[24] S.-W. Hwang, H.-H. Jung, S.-H. Hyun, Y.-S. Ahn, J. Sol-Gel Sci. Technol. 41 
(2007) 139-146.

[25] S.D. Bhagat, Y.-H. Kim, Y.-S. Ahn, J.-G. Yeo, Appl. Surf. Sci. 253 (2007) 3231-3236.

[26] C.E. Kim, J.S. Yoon, H.J. Hwang, J. Sol-Gel Sci. Technol. 49 (2008) 47-52.

[27] S.D. Bhagat, K.-T. Park, Y.-H. Kim, J.-S. Kim, J.-H. Han, Solid State Sci. 10 (2008) 1113-1116.

[28] U.K.H. Bangi, A. Venkateswara Rao, A. Parvathy Rao, Sci. Technol. Adv. Mater. 9 (2008) 1-10.

[29] J.L. Gurav, A.V. Rao, U.K.H. Bangi, J. Alloys Compd. 471 (2009) 296-302.

[30] A. Parvathy Rao, A. Venkateswara Rao, J. Mater. Sci. 45 (2009) 51-63.

[31] L.-J. Wang, S.-Y. Zhao, M. Yang, Mater. Chem. Phys. 113 (2009) 485-490.

[32] A.M. Anderson, M.K. Carroll, in:, M.A. Aegerter, N. Leventis, M.M. Koebel (Eds.), Aerogel Handb., Springer New York, 2011, pp. 47-77.

[33] H. Maleki, L. Durães, A. Portugal, J. Non. Cryst. Solids 385 (2014) 55-74.

[34] W.J. Malfait, S. Zhao, R. Verel, S. Iswar, D. Rentsch, R. Fener, Y. Zhang, B. Milow, M.M. Koebel, Chem. Mater. 27 (2015) 6737-6745.

[35] T. Woignier, J. Phalippou, J. Non. Cryst. Solids 100 (1988) 404-408.

[36] T. Woignier, H. Phalippou J, H. Hdach, G.W. Scherer, Mater. Res. Soc. 180 (1990) 1087-1099.

[37] P.J. Davis, C. Jeffrey Brinker, D.M. Smith, J. Non. Cryst. Solids 142 (1992) 189196.

[38] P.J. Davis, C.J. Brinker, D.M. Smith, R.A. Assink, J. Non. Cryst. Solids 142 (1992) 197-207.

[39] S. Hæreid, E. Nilsen, M.A. Einarsrud, J. Porous Mater. 2 (1995) 315-324.

[40] S. Hæreid, J. Anderson, M.A. Einarsrud, D.W. Hua, D.M. Smith, J. Non. Cryst. Solids 185 (1995) 221-226.

[41] S. Hæreid, M. Dahle, S. Lima, M.-A. Einarsrud, J. Non. Cryst. Solids 186 (1995) 96-103.

[42] S. Haereid, E. Nilsen, M.A. Einarsrud, J. Non. Cryst. Solids 204 (1996) 228-234.

[43] G. Pajonk, A.V. Rao, B. Sawant, J. Non. Cryst. Solids 209 (1997) 40-50.

[44] S.H. Haereid, E. Nilsen, V. Ranum, M. Einarsrud, J. Sol-Gel Sci. Technol. 8 (1997) 153-157.

[45] M. Einarsrud, E. Nilsen, J. Sol-Gel Sci. Technol. 322 (1998) 317-322.

[46] M.-A. Einarsrud, E. Nilsen, J. Non. Cryst. Solids 226 (1998) 122-128.

[47] Einarsrud Mari-ann; Kirkedelen May Britt; Nilsen Elin; Mortensen Kell; Samseth Jon, J. Non. Cryst. Solids 231 (1998) 10-16.

[48] D.J. Suh, T. Park, J. Mater. Sci. 18 (1999) 1473-1475.

[49] M.-A. Einarsrud, E. Nilsen, A. Rigacci, G.. Pajonk, S. Buathier, D. Valette, M. Durant, B. Chevalier, P. Nitz, F. Ehrburger-Dolle, J. Non. Cryst. Solids 285 (2001) 1-7.

[50] A. Rigacci, M.A. Einarsrud, E. Nilsen, R. Pirard, F. Ehrburger-Dolle, B. Chevalier, J. Non. Cryst. Solids 350 (2004) 196-201.

[51] G. Reichenauer, J. Non. Cryst. Solids 350 (2004) 189-195.

[52] A. Venkateswara Rao, A. Parvathy Rao, M.M. Kulkarni, J. Non. Cryst. Solids 350 (2004) 224-229.

[53] S. Smitha, P. Shajesh, P.R. Aravind, S.R. Kumar, P.K. Pillai, K.G.K. Warrier, Microporous Mesoporous Mater. 91 (2006) 286-292.

[54] S. Smitha, P. Shajesh, S.R. Kumar, P. Krishna Pillai, K.G.K. Warrier, J. Porous Mater. 14 (2007) 1-6. 
[55] R.A. Strøm, Y. Masmoudi, A. Rigacci, G. Petermann, L. Gullberg, B. Chevalier, M.-A. Einarsrud, J. Sol-Gel Sci. Technol. 41 (2007) 291-298.

[56] J. Estella, J.C. Echeverría, M. Laguna, J.J. Garrido, Microporous Mesoporous Mater. 102 (2007) 274-282.

[57] F. He, H. Zhao, X. Qu, C. Zhang, W. Qiu, J. Mater. Process. Technol. 209 (2009) 1621-1626.

[58] P.B. Sarawade, J.K. Kim, A. Hilonga, H.T. Kim, Korean J. Chem. Eng. 27 (2010) 1301-1309.

[59] P.B. Sarawade, J.K. Kim, A. Hilonga, D.V. Quang, H.T. Kim, Microporous Mesoporous Mater. 139 (2011) 138-147.

[60] G.M. Pajonk, E. Elaloui, P. Achard, B. Chevalier, J.-L. Chevalier, M. Durant, J. Non. Cryst. Solids 186 (1995) 1-8.

[61] S. Brunauer, P.H. Emmett, E. Teller, J. Am. Chem. Soc. 60 (1938) 309-319.

[62] E.P. Barrett, L.G. Joyner, P.P. Halenda, J. Am. Chem. Soc. 73 (1951) 373-380.

[63] G. Reichenauer, in:, Aegerter; M. A.; Leventis; N.; Koebel; M. M. (Ed.), Aerogels Handb., Springer New York, 2011, pp. 449-498.

[64] A. Ayral, J. Phalippou, T. Woignier, J. Mater. Sci. 27 (1992) 1166-1170.

[65] J.D. van Beek, J. Magn. Reson. 187 (2007) 19-26.

[66] W.J. Malfait, R. Verel, M.M. Koebel, J. Phys. Chem. C 118 (2014) 2554525554.

[67] K. Hyun, S.H. Kim, K.H. Ahn, S.J. Lee, J. Nonnewton. Fluid Mech. 107 (2002) $51-65$.

[68] K. Hyun, M. Wilhelm, C.O. Klein, K.S. Cho, J.G. Nam, K.H. Ahn, S.J. Lee, R.H. Ewoldt, G.H. McKinley, Prog. Polym. Sci. 36 (2011) 1697-1753.

[69] G. Tkalec, Ž. Knez, Z. Novak, RSC Adv. 5 (2015) 77362-77371.

[70] A.C. Pierre, E. Elaloui, G.M. Pajonk, Langmuir 14 (1998) 66-73.

[71] S.K. Freltoft, T; Kjems, J.K; Sinha, Phys. Rev. B 33 (1986) 269-275.

[72] T. Woignier, J. Phalippou, R. Vacher, J. Pelous, E. Courtens, J. Non. Cryst. Solids 121 (1990) 198-201. 
Table 1. Influence of aging time and temperature on the physical properties of silica aerogel.

\begin{tabular}{|c|c|c|c|c|}
\hline $\begin{array}{l}\text { Aging time } \\
\text { (hrs.) }\end{array}$ & $\begin{array}{l}\text { Bulk density } \\
\left(\mathrm{g} / \mathrm{cm}^{3}\right)^{\mathrm{a}}\end{array}$ & $\begin{array}{l}\mathbf{S}_{\text {BET }} \\
\left(\mathbf{m}^{2} / \mathbf{g}\right)^{b}\end{array}$ & $\begin{array}{l}\text { Pore diameter } \\
(\mathrm{nm})^{\mathrm{c}}\end{array}$ & $\begin{array}{l}\text { Pore volume } \\
\left(\mathrm{cm}^{3} / \mathrm{g}\right)^{\mathrm{d}}\end{array}$ \\
\hline & \multicolumn{4}{|c|}{ Aging temperature $-55^{\circ} \mathrm{C}$ (APD) } \\
\hline 2 & 0.354 & 907 & 10.3 & 2.3 \\
\hline 4 & 0.303 & 887 & 12.6 & 2.8 \\
\hline 6 & 0.285 & 863 & 13.9 & 3.0 \\
\hline 8 & 0.253 & 856 & 16.1 & 3.5 \\
\hline 16 & 0.145 & 850 & 30.1 & 6.4 \\
\hline \multirow[t]{2}{*}{24} & 0.136 & 846 & 32.4 & 6.9 \\
\hline & \multicolumn{4}{|c|}{ Aging temperature $-65^{\circ} \mathrm{C}$ (APD) } \\
\hline 2 & 0.309 & 901 & 12.1 & 2.7 \\
\hline 4 & 0.255 & 890 & 15.4 & 3.4 \\
\hline 6 & 0.211 & 883 & 19.2 & 4.2 \\
\hline 8 & 0.181 & 858 & 23.4 & 5.0 \\
\hline 16 & 0.123 & 844 & 36.2 & 7.6 \\
\hline \multirow[t]{2}{*}{24} & 0.118 & 816 & 39.1 & 8.0 \\
\hline & \multicolumn{4}{|c|}{ Aging temperature $-75^{\circ} \mathrm{C}$ (APD) } \\
\hline 2 & 0.238 & 885 & 16.7 & 3.7 \\
\hline 4 & 0.205 & 878 & 19.9 & 4.4 \\
\hline 6 & 0.189 & 865 & 22.1 & 4.8 \\
\hline 8 & 0.158 & 864 & 27.0 & 5.8 \\
\hline 16 & 0.111 & 860 & 39.6 & 8.5 \\
\hline \multirow[t]{2}{*}{24} & 0.111 & 838 & 40.6 & 8.5 \\
\hline & \multicolumn{4}{|c|}{ Aging temperature - $65^{\circ} \mathrm{C}(\mathrm{SCD})$} \\
\hline 2 & 0.092 & 972 & 42.7 & 10.4 \\
\hline 4 & 0.091 & 948 & 44.3 & 10.5 \\
\hline 6 & 0.092 & 902 & 46.0 & 10.4 \\
\hline 8 & 0.088 & 892 & 48.7 & 10.9 \\
\hline 16 & 0.088 & 872 & 49.8 & 10.9 \\
\hline 24 & 0.089 & 862 & 49.8 & 10.7 \\
\hline
\end{tabular}

Estimated uncertainties: ${ }^{\mathrm{a}}$ bulk density, $5 \%$ relative; ${ }^{\mathrm{b}} \mathrm{S}_{\mathrm{BET}}$, around $50 \mathrm{~m}^{2} / \mathrm{g}$; ${ }^{\mathrm{c}}$ pore diameter, $10 \%$ relative; ${ }^{\mathrm{d}}$ pore volume, $10 \%$ relative. 


\section{Figure captions:}

Figure 1. Process scheme for the synthesis of silica aerogel.

Figure 2. Ambient dried silica aerogels for different aging times and temperatures. The same mass of sample (0.2 gram) is shown for all samples. The supercritically dried aerogels are shown in Figure S1.

Figure 3. Influence of aging time and temperature on (a) the bulk density and (b) pore volume of silica aerogels.

Figure 4. TEM images of ambient dried silica aerogels aged at $65^{\circ} \mathrm{C}$ for (a) 2 hours and (b) 24 hours.

Figure 5. Influence of aging time on the nitrogen sorption isotherms of silica aerogel aged at $65^{\circ} \mathrm{C}$ for (a) APD and (b) SCD. The arrows indicate the increase in aging time. Figure 6. Influence of aging time and temperature on (a) surface area and (b) average pore diameter.

Figure 7. SAXS spectra as a function of the momentum transfer vector $\mathrm{q}$ of ambient dried silica aerogels aged at $65^{\circ} \mathrm{C}$ for 6 aging times.

Figure 8. Influence of aging time and temperature on (a) Fractal dimension $\left(\mathrm{d}_{\mathrm{fl}}\right)$ and (b) Characteristic cluster length scale $\left(\zeta_{1}\right)$. The values are extracted from the SAXS spectra using Equation (3). Estimated uncertainties for $d_{f 1}$ and $\zeta_{1}$ are $0.2 \%$ and $2 \%$ relative. Figure 9. (a) Quantitative solid state ${ }^{1} \mathrm{H}$ MAS NMR spectra and (b) ${ }^{1} \mathrm{H}^{29}{ }^{29} \mathrm{Si}$ cross polarization MAS NMR spectra of ambient dried silica aerogels aged at $65^{\circ} \mathrm{C}$ for 6 aging times. The inset shows the $\mathrm{Q}^{3}$ peak area and the arrow indicates the decrease in $\mathrm{Q}^{3}$ with increasing aging time.

Figure 10. Strain sweep measurements of silica alcogels aged at $65^{\circ} \mathrm{C}$ for 6 aging times. 
Figures:

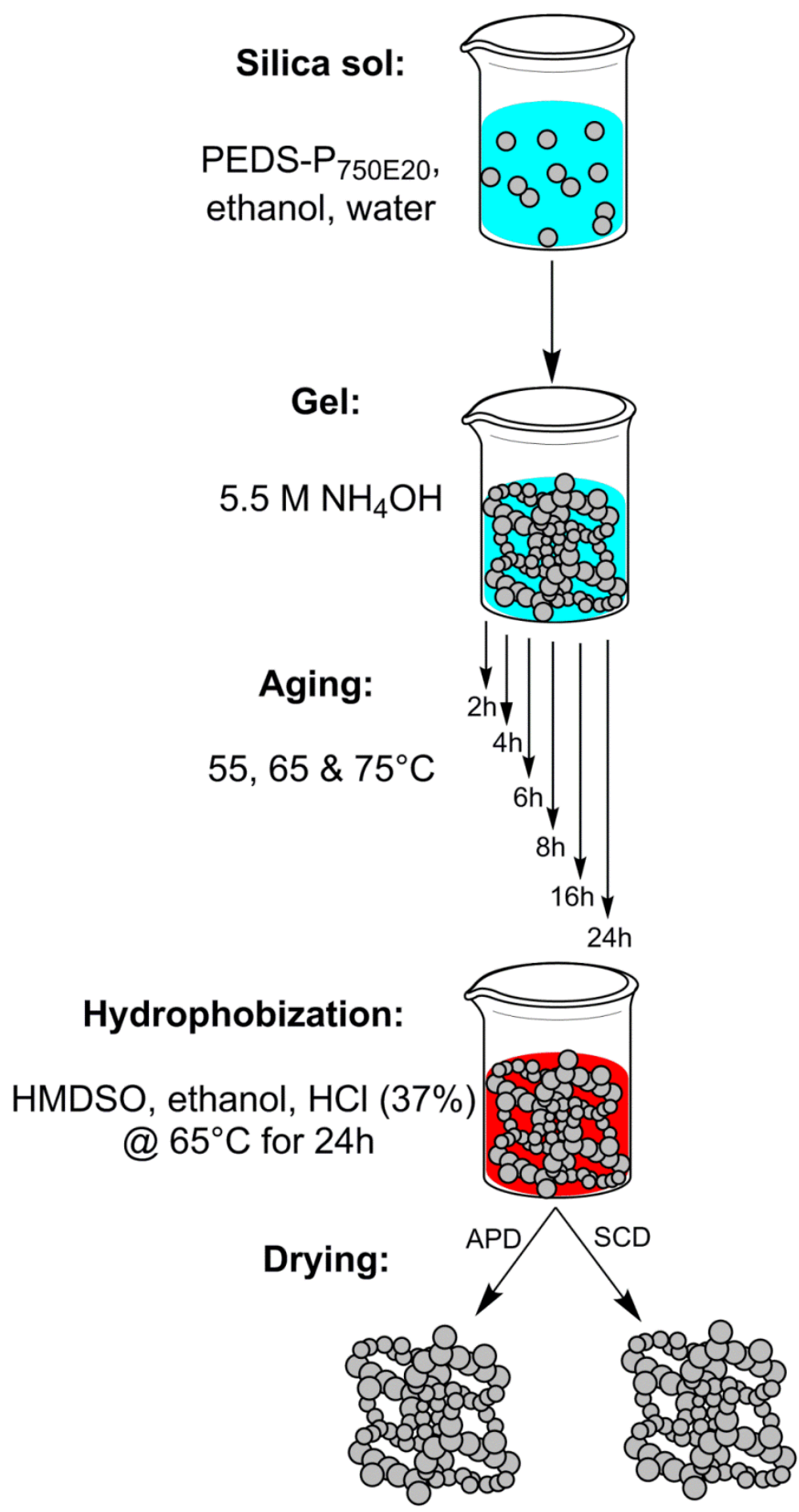

Figure 1. 


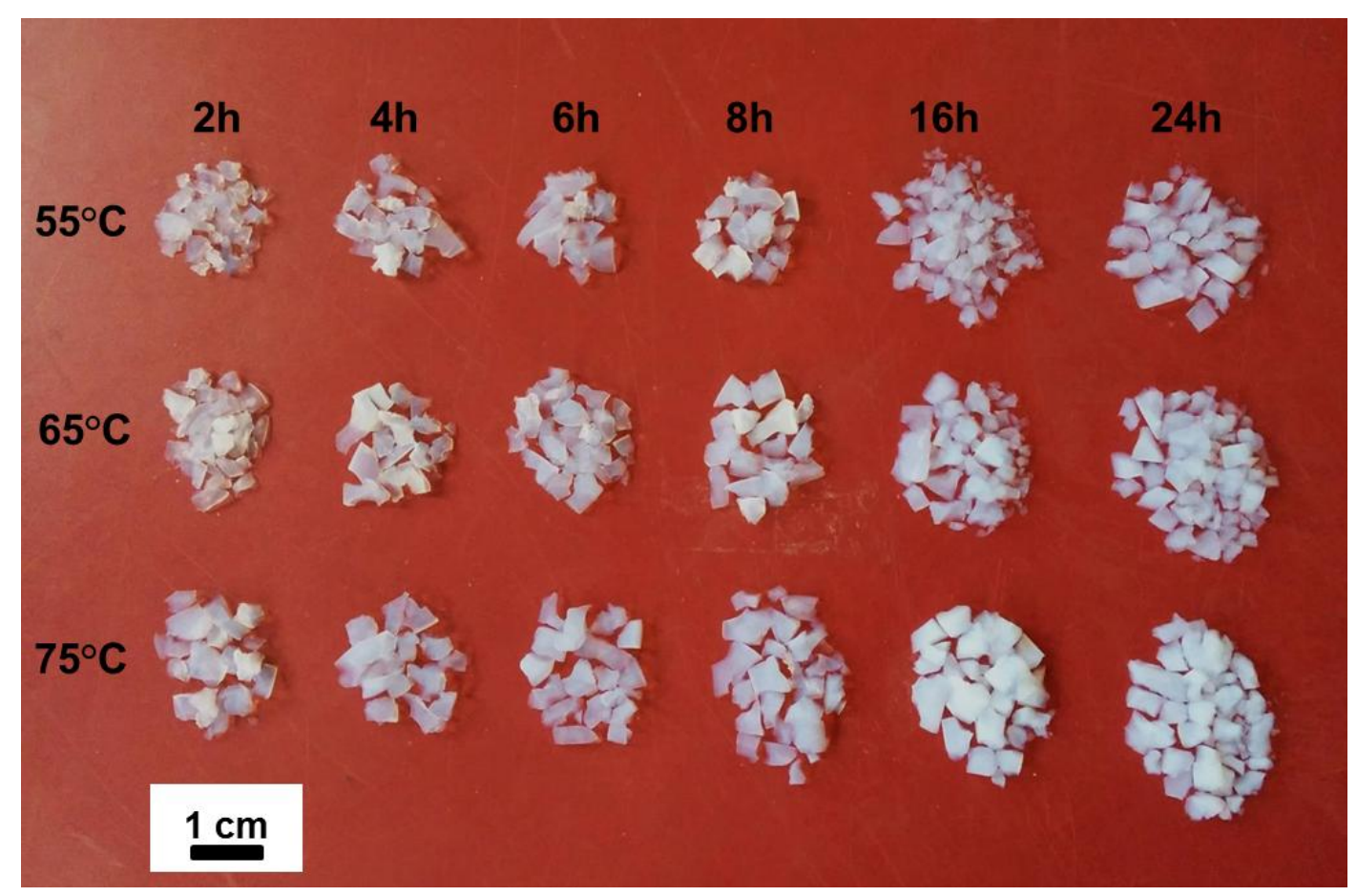

Figure 2. 

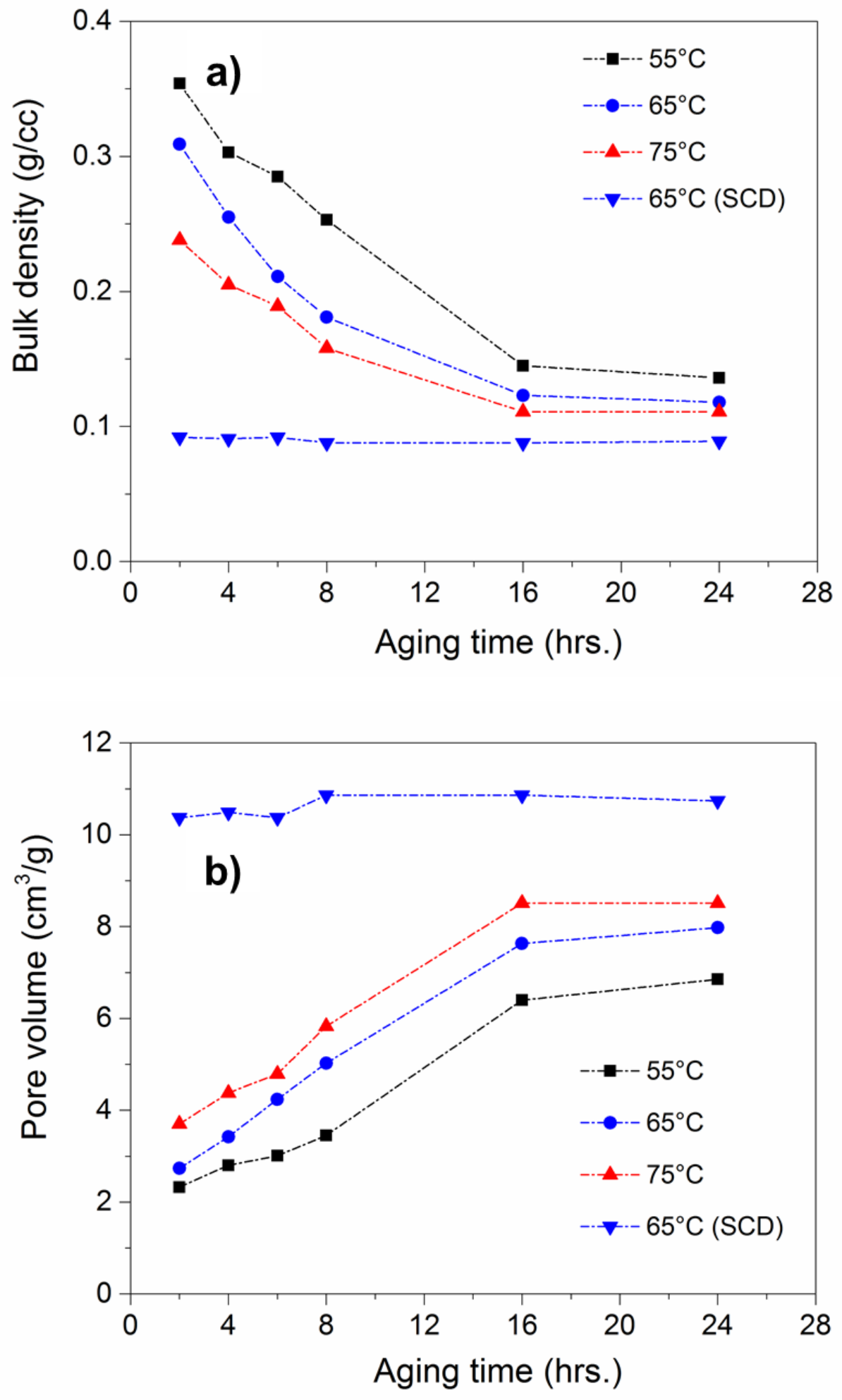

Figure 3. 

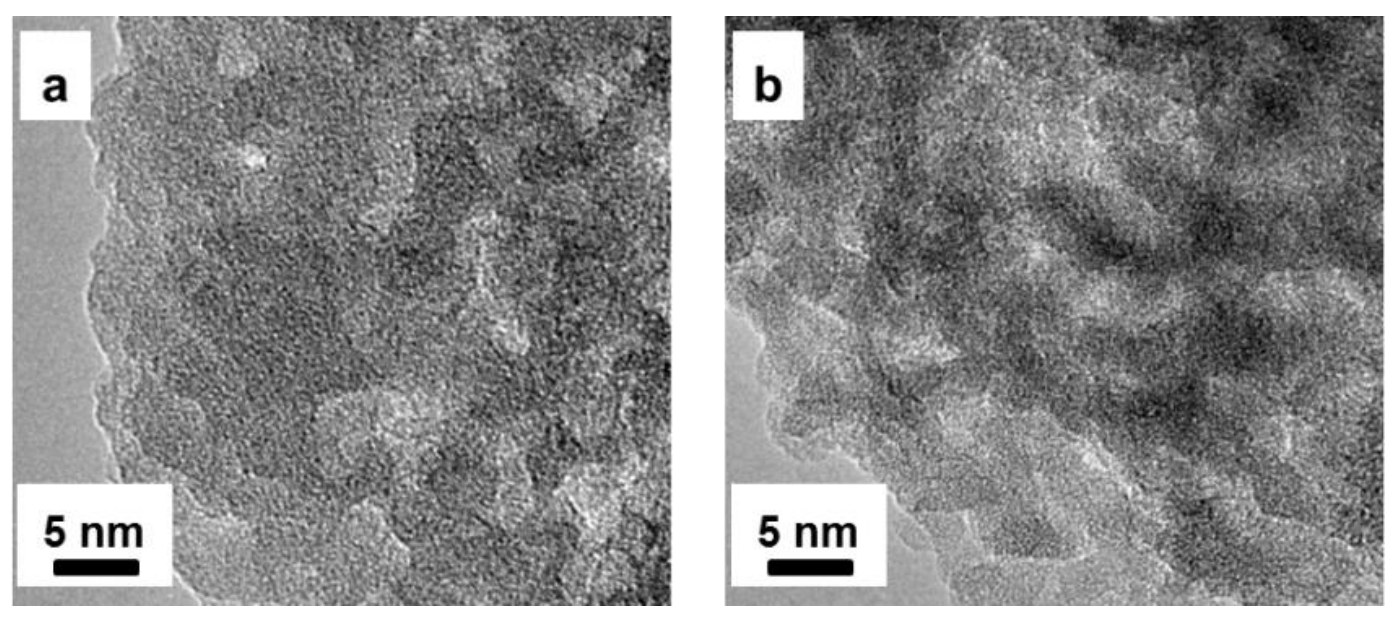

Figure 4. 

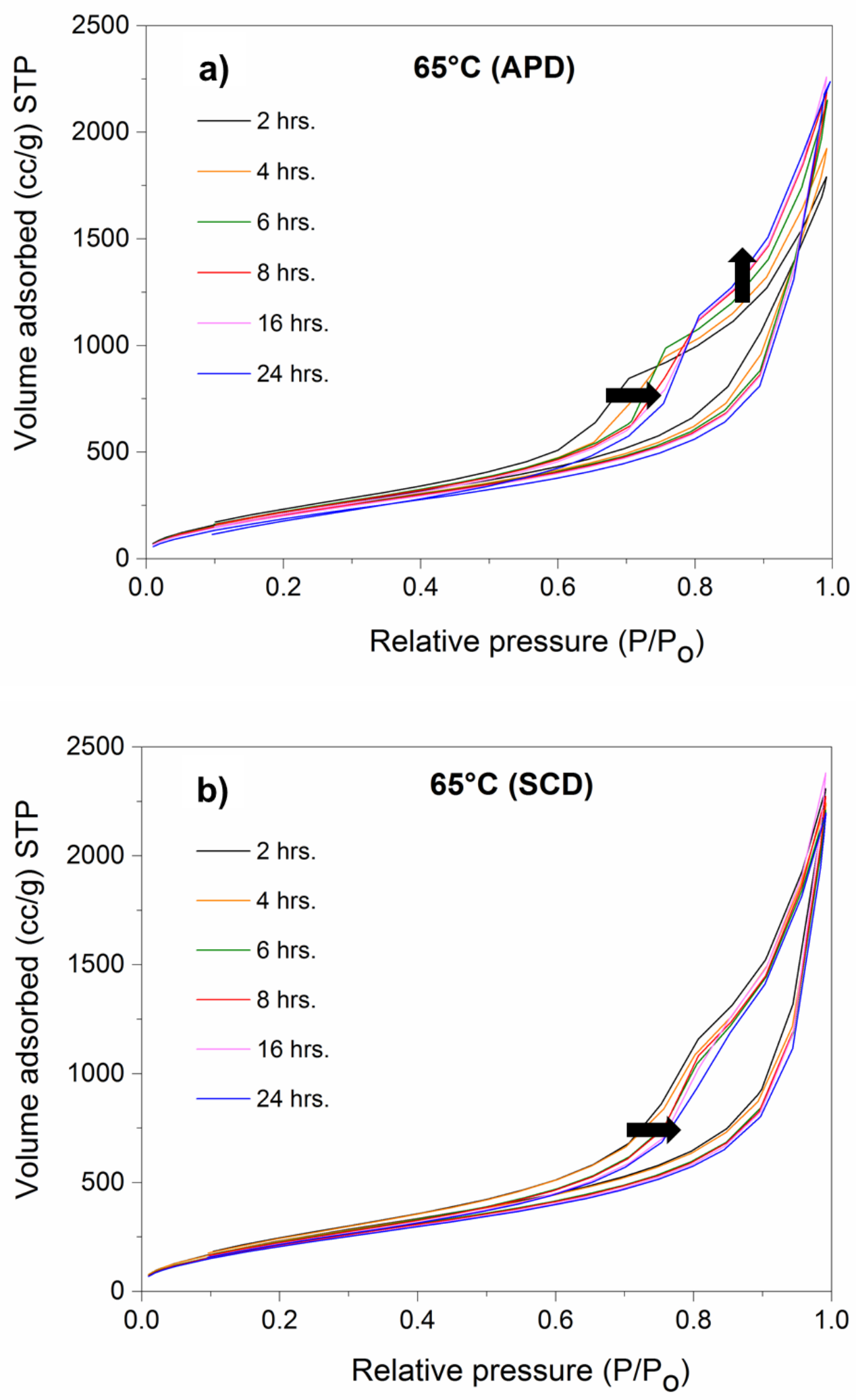

Figure 5. 

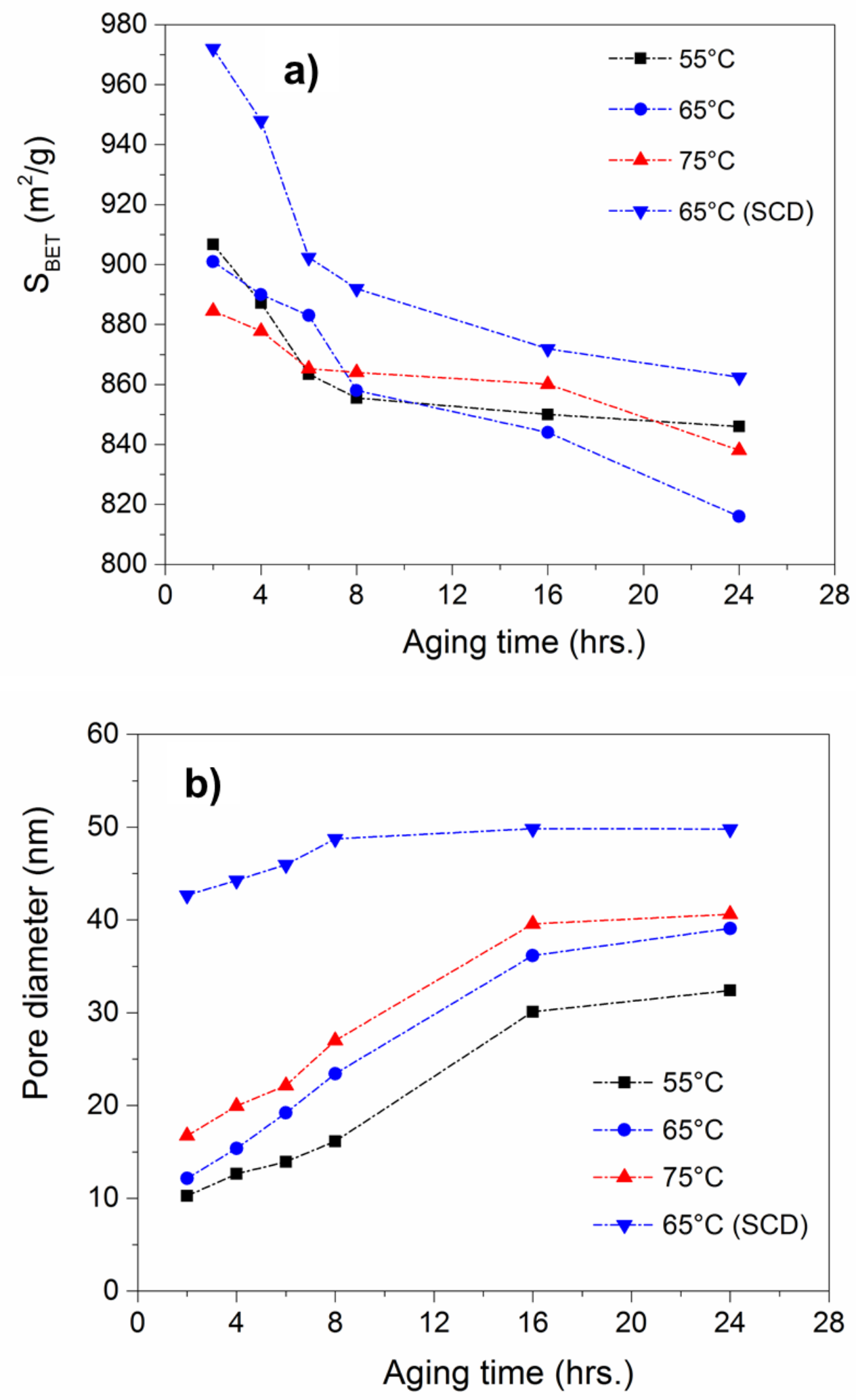

Figure 6. 


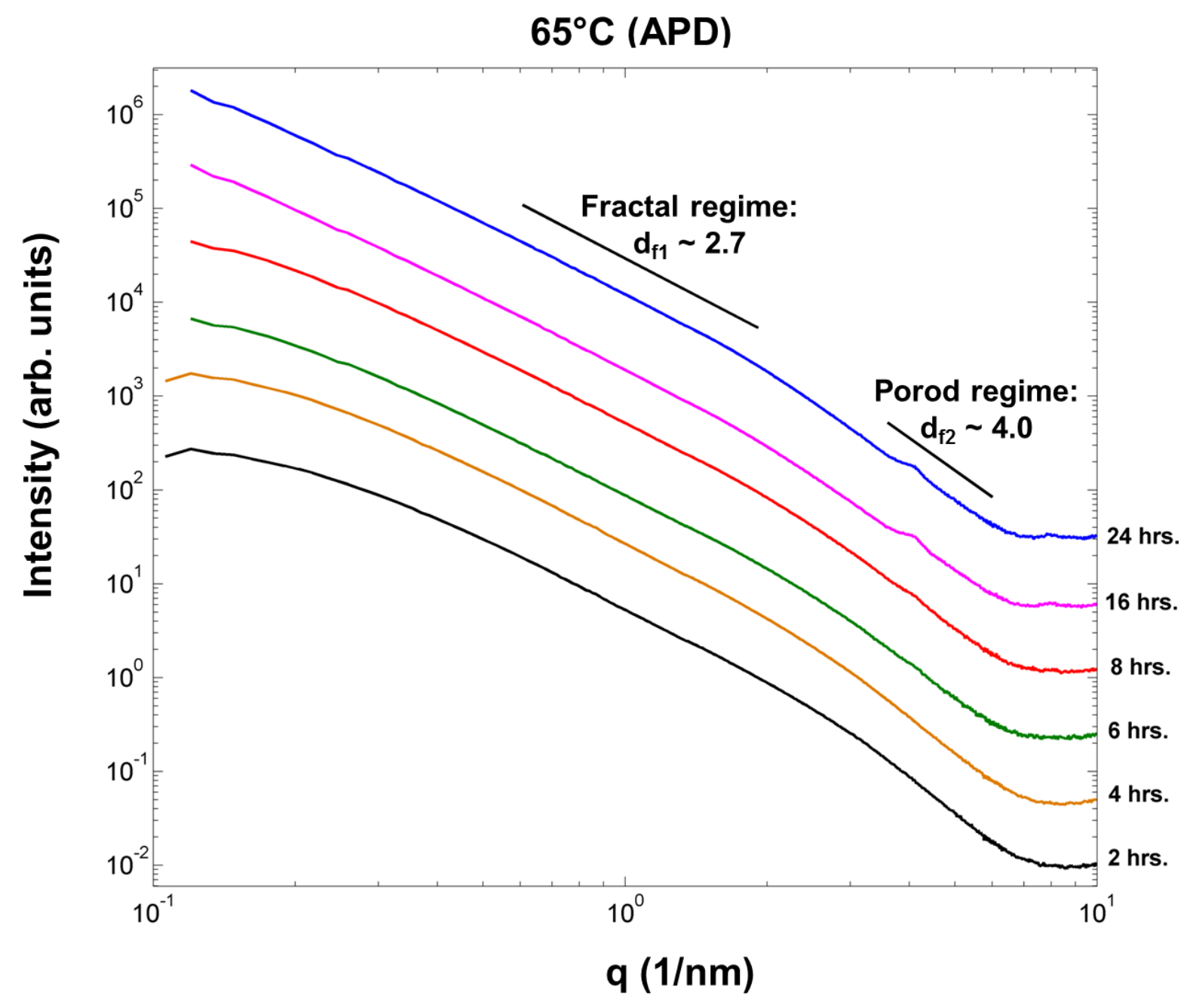

Figure 7. 

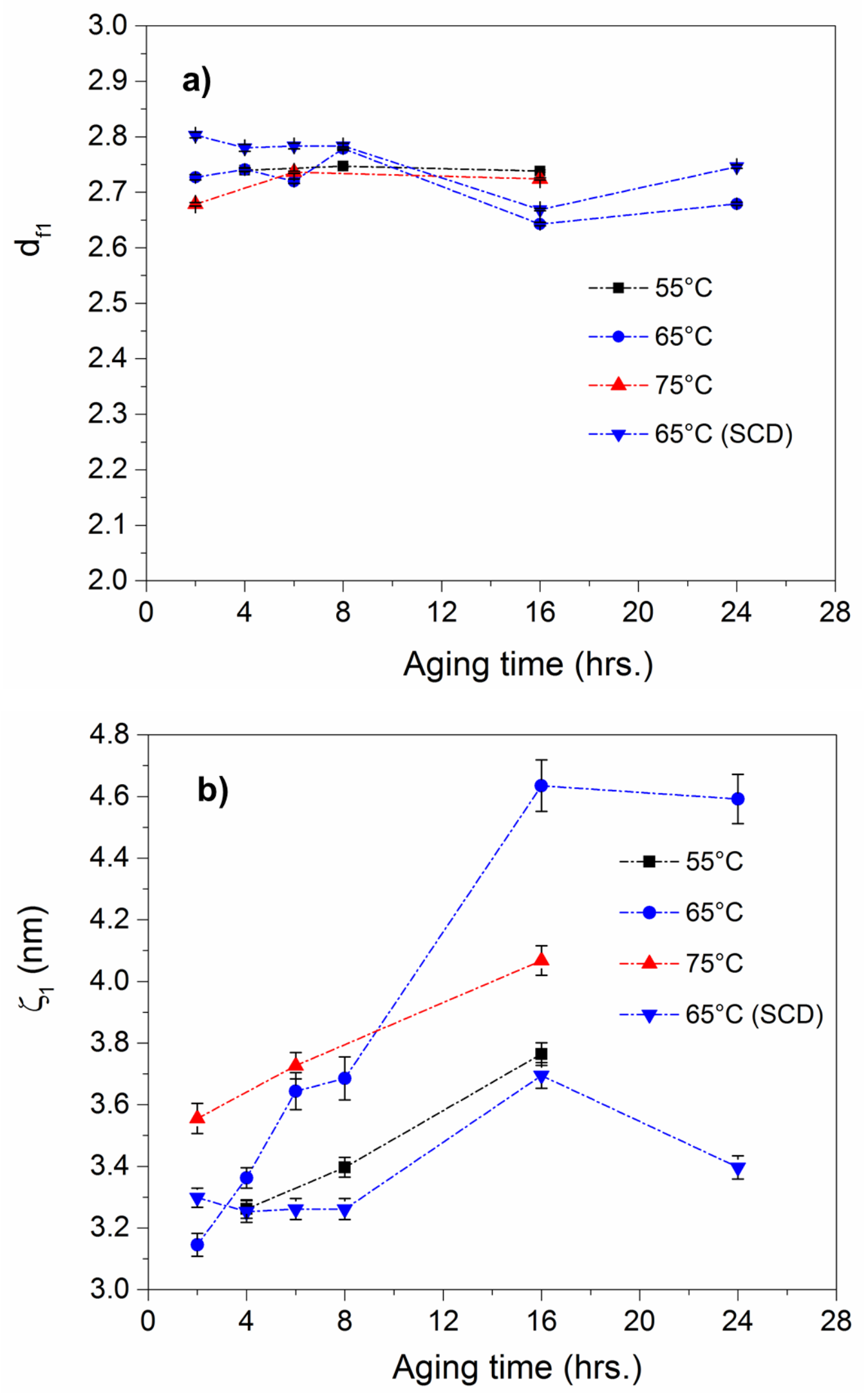

Figure 8. 

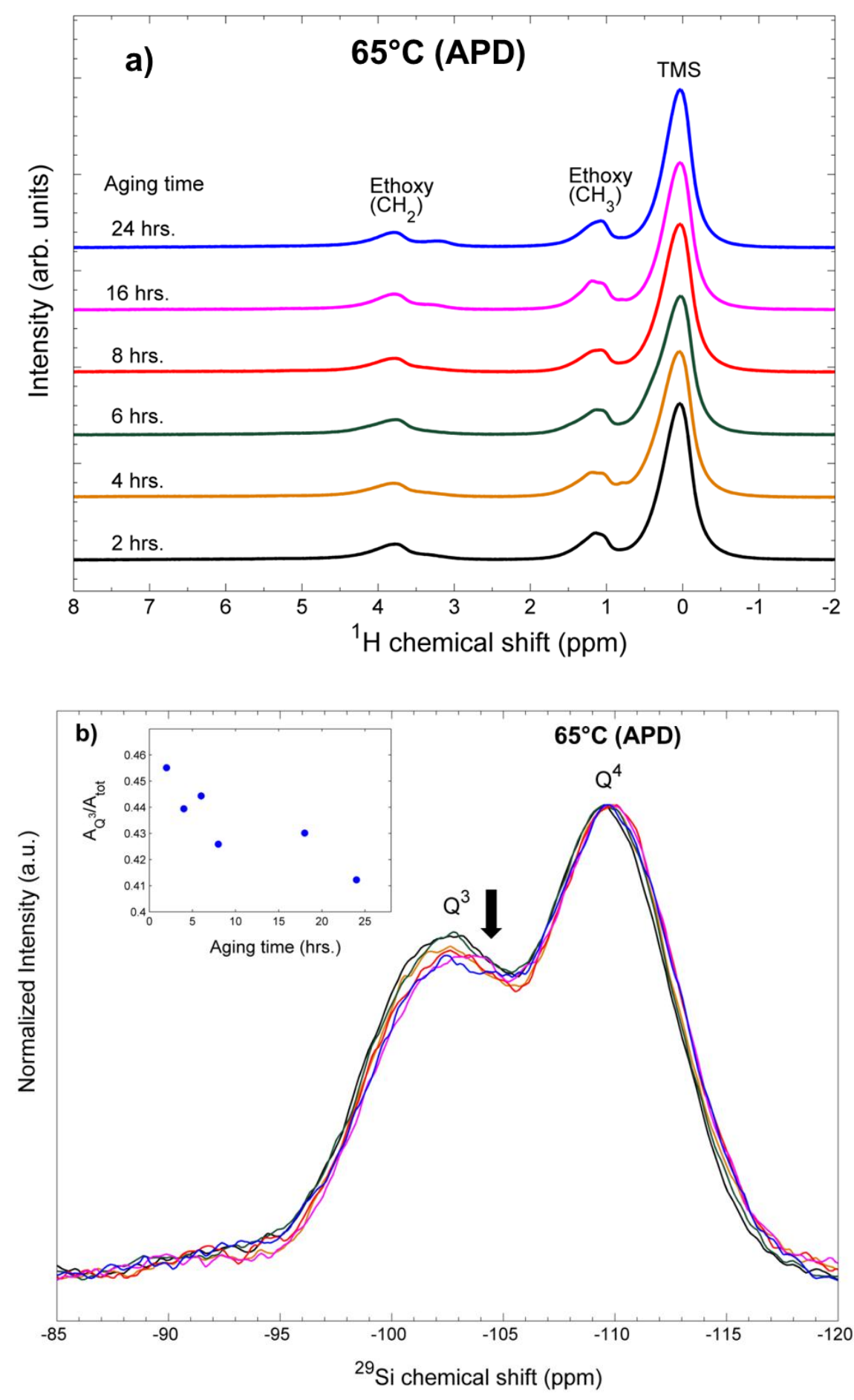

Figure 9. 

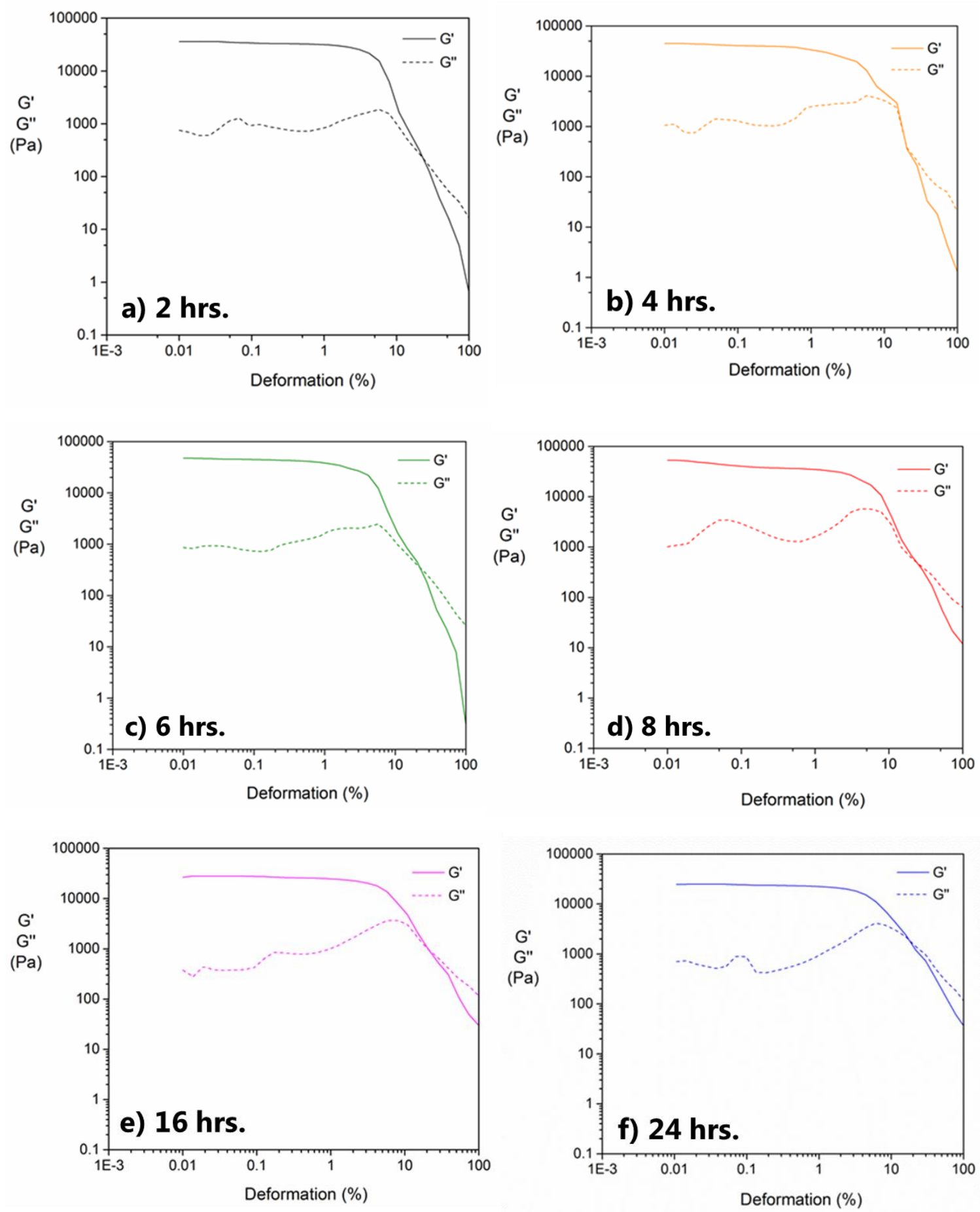

Figure 10. 